\title{
BRIDGING THE GAP BETWEEN TECHNOLOGY AND SCIENCE WITH EXAMPLES FROM ECOLOGY AND BIODIVERSITY
}

\author{
LAURa L. Downey and DeAna PENnINGTON \\ University of New Mexico, LTER Network Office Department of Biology, MSC03 2020 \\ University of New Mexico Albuquerque, NM 87131-0001, laura.downey@dhs.gov, \\ dpennington@lternet.edu
}

\begin{abstract}
Early informatics initiatives focused primarily on the application of technology and computer science to a specific domain; modern informatics has broadened to encompass human and knowledge dimensions. Application of technology is but one aspect of informatics. Understanding domain members' issues, priorities, knowledge, abilities, interactions, tasks, and work environments is another aspect, one that directly impacts application success. Involving domain members in the design and development of technology in their domain is a key factor in bridging the gap between technology and science. This usercentered design (UCD) approach in informatics is presented via an ecoinformatics case study in three areas: collaboration, usability, and education and training.
\end{abstract}

Keywords. - Collaboration, ecoinformatics, science and technology, training, usability, user-centered design.

The French term "informatique" first appeared in the 1960s, and referred to "the application of computing to the communication processes used by scientists in exchanging information and data among themselves." Computing applications, adoption and usage remained the primary focus of informatics programs for many years. In the last decade, the focus has expanded to include cognitive, social and human dimensions. For example, at the School of Informatics at The University of Edinburgh, informatics is defined as "the study of how natural and artificial systems store, process and communicate information." The Indiana University South Bend informatics program defines informatics along three dimensions: ${ }^{3}$

- Understanding the impact that technology has on people

- The development of new uses for technology

- The application of information technology in the context of another field

\footnotetext{
${ }^{1} \mathrm{http}: / /$ informatics.buffalo.edu/school/informatics.asp.

2 http://www.inf.ed.ac.uk/about/.

${ }^{3} \mathrm{http}: / /$ www.informatics.iusb.edu/.
}

Within this broad perspective of informatics that encompasses humans, technology and knowledge, the Science Environment for Ecological Knowledge (SEEK) project (Michener et al. 2007) bridged the gap between technology and science by employing a user-centered design approach. Informatics began with scientists, and the usercentered design approach brings scientists to the forefront of the application, design, and development of technology in science.

\section{USER-CENTERED DESIGN}

User-centered design (Stone et al. 2005) is a design approach to creating systems, software, and technology that actively seeks to understand and involve the target users in the design and development process. It includes understanding their abilities, knowledge, needs, and concerns, as well as their interactions, tasks, and work environments. Example methods in UCD are surveys, field studies, structured feedback sessions, task analysis, and usability testing of software with target users. Many UCD techniques have been applied in the process of developing the SEEK project.

The benefits of UCD are well documented in the human factors and usability literature, in 
books, and in many consultants' white papers. As one example, Bias and Mayhew (2005) contains a nice cross-section of case studies and research that detail returns on usability investments. Many corporations have come to realize the return on investment that the UCD process offers. The fields of human factors and industrial engineering and usability engineering have increased significantly in the past 20 years. There is an international standard (ISO 13407) ${ }^{4}$ which outlines the general process of user-centered design. Basic business benefits, as summarized by the Usability Professionals Association, are:

- Increased productivity

- Increased sales and revenues

- Decreased training and support costs

- Reduced development time and costs

- Reduced maintenance costs

- Increase customer satisfaction

Research teams that include UCD when developing software for scientists benefit from less resources being required for development and maintenance; and scientists who are the users will benefit from increased productivity. However, we believe strongly that the importance of UCD in science goes beyond these basics. The UCD process is important to science because:

- Technology should make a scientist's job easier, not get in the way

- Technology should help scientists work faster, better and smarter

- Technology should be easily exploited by scientists to enable new analyses and discoveries

There are various models of UCD, some with specific details, and some providing frameworks. Figure 1 offers an example UCD process followed by the Usability and Accessibility Center of Michigan State University ${ }^{5}$. It has five phases and also demonstrates the inherent iterative nature of UCD. A variety of activities can be selected for each phase.

\footnotetext{
${ }^{4}$ ISO 13407 is an international standard produced by the International Organization for Standardization. The subject of the standard 13407 is "Human-centred design processes for interactive systems. (See: http://www.iso.org/iso/iso_catalogue/catalogue_tc/catalogue_detail.ht m? csnumber $=21197$ )

${ }^{5}$ http://usability.msu.edu/approach.asp
}

\section{THE SEEK PROJECT}

The SEEK project is a multi-institutional collaboration sponsored by the National Science Foundation that is (1) creating cyberinfrastructure and applications for ecological, environmental, and biodiversity research, and (2) educating the ecological community about ecoinformatics. Figure 2 provides an overview of the SEEK architecture which illustrates knowledge, technology and community all working together to enable science and promote collaboration.

A major focus of SEEK is the enhancement of a scientific workflow application called Kepler (Altintas et al. 2004, Ludäscher 2006). Kepler is an open-source modeling and analysis tool for creating, visualizing, executing, and documenting scientific workflows. A scientific workflow is a collection of data flow and analytical steps that formalizes the research process. Two real-world research problems, one from ecology and one from biodiversity science are being pursued to demonstrate how technology can enhance and enable scientific research. Semantic mediation is a primary infrastructural research area, with the goal of providing enhanced machine operations, relieving the manual computational analysis and data integration burden from scientists. The purpose of the semantic mediation system (SMS) (Bowers et al. 2004, Bowers and Ludäscher 2003, 2004) in Kepler is to (1) help scientists discover relevant data and processing components for use in constructing scientific workflows, (2) automate or semi-automate the merging of heterogeneous data sets, and (3) perform automatic transformation in a scientific workflow. This technology application and usage is not done in a vacuum. Scientists interact with the technology to achieve their objectives and therefore should be part of the design and development process so that the technology can be fully and usefully exploited. This paper uses the SEEK project as a case study to report on bridging the gap between technology and science with a focus on the user centered design approach. 


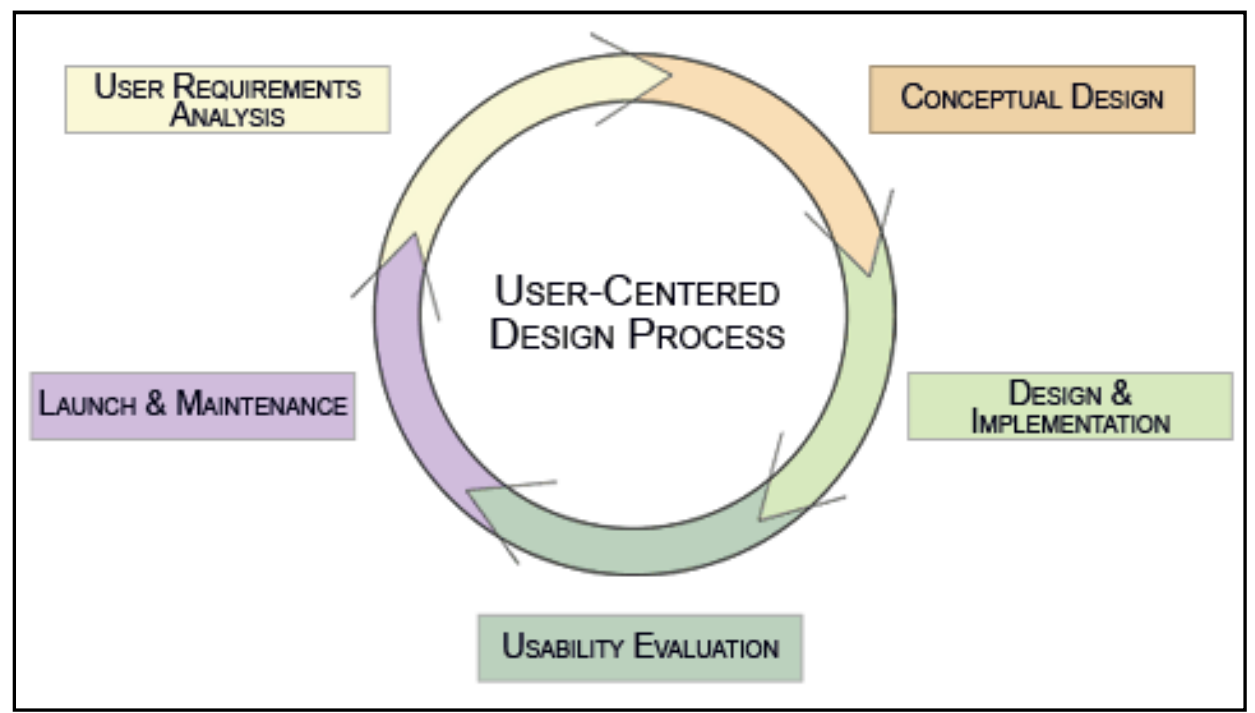

Figure 1. User-centered design process followed by the Usability and Accessibility Center, Michigan State University.

\section{BUILDING BRIDGES}

One of the initial steps that the SEEK project took to ensure that scientists' concerns and issues would be integral to the project was to put some of those scientists on the SEEK team. Their perspective is an integral part of application design, helping to shape and formulate current and future directions. The cross-disciplinary team forms the foundation of our bridge between science and technology. The SEEK project built upon that foundation by pursuing additional collaborations with the scientific community, applying usability engineering techniques to its technology products, and conducting education and training in ecoinformatics.

\section{Collaboration}

Early in the project, SEEK initiated collaborative activities with two groups of scientists. Each group had real-world research problems of interest to the project because their basic needs were in technical research areas targeted by SEEK. Interactions with these communities allowed developers to delineate needs more clearly, focus development on specific articulated problems, and test solutions against real problems. The test beds were absolutely critical for grounding theoretical solutions devised by computer science researchers within the more comprehensive solutions developed to meet the full set of requirements.

Ecological niche modeling research group

Ecological niche modeling is an approach for understanding and predicting species' present geographic distributions (Nix 1986, Carpenter et al. 1993) and distributions under scenarios of change, including transplantation to another continent as invasive species (Beerling et al. 1995, Peterson and Vieglais 2001) or under changed climatic conditions (Martínez-Meyer et al. 2004, Araújo et al. 2005). Numerous conceptual approaches and software tools can be used in ecological niche modeling (Nix 1986, Walker and Cocks 1991, Carpenter et al. 1993). SEEK selected this community for its prototype application because the global-scale analyses in which they are engaged were complex and required substantial manual data discovery and processing. As such, clear gains could be made through applying cutting-edge technology.

The group recruited for collaboration included 20 leading researchers from around the world (United States, Mexico, Europe, South Africa, Australia, New Zealand, etc.). SEEK held three working meetings with this group: (1) a full group meeting where analysis and modeling tasks were discussed and important datasets, algorithms, and 
analytical environments were identified, (2) a small working group meeting where a specific research problem was fully specified from a workflow perspective, and (3) a full group meeting where prototypes were tested for appropriate functionality and usability (Downey 2007).

Through the first two meetings, technical problems and tasks associated with ecological niche modeling were identified as:

- Labor-intensive data preprocessing and preparation

- Distributed data, archived in dozens of museum collections and environmental repositories

- Heterogeneous computing environments required in the workflow (e.g., C and Java programs, scripts in Matlab, SAS and R, and GIS analyses.

- Compute-intensive algorithm execution for multiple species, under multiple parameter sweeps, and when the algorithm is stochastic many iterations to construct a distribution of results for statistical comparison.

These needs of the ecological niche modeling community drove development of the Kepler workflow system (Pennington et al. 2007), a problem-solving environment making use of visual modeling to construct workflows that access distributed data within a grid system and which allows integration of heterogeneous computing environments.

\section{Biodiversity analysis research group}

Biodiversity is a measure of the numbers and kinds of species occurring at a particular place and time. Patterns of biodiversity are known to occur correlated with climate, productivity, evolutionary history, glacial history, and a host of other environmental characteristics. Biodiversity is in documented decline worldwide (Barbaut and Sastrapadja 1995, Pimm and Raven 2000), but understanding the causes and consequences of this depends on integrating all of the relevant ecological characteristics with all available species information over broad areas (Waide et al. 1999). Most of the relevant data was collected by independent researchers working at small field sites over decades. Hence, most biodiversity researchers invest a good deal of effort in simply gathering and integrating the available data to assess where gaps exist that could be addressed through collecting additional data.
This group recruited to work with SEEK had a very different flavor than the previous group. Development of solutions to help resolve semantic problems requires a truly interdisciplinary approach to understanding and representing domain concepts in ways that are formal and computationally tractable. The necessary level of engagement with technical personnel is fairly high; therefore, domain experts with at least some demonstrated technical skill were recruited. We held two small group working meetings with these scientists, where we meticulously examined multiple datasets and discussed the meaning of every attribute in those datasets, where they were derived from, and how they would need to be modified for integration. The group provided scripts that were used to manipulate data in prior analyses, and designed a new analysis from which information was gathered.

Technical problems associated with regional and global scale biodiversity analyses are:

- Distributed datasets

- Datasets that are heterogeneous at the physical, logical, and semantic levels

- Labor-intensive dataset integration

- Undocumented and non-repeatable manual integration steps

The needs of the biodiversity analysis research group have driven development of SEEK's observation ontologies (Madin et al. submitted) and the SMS. They also helped inform design of semi-automated integration tools within Kepler and emphasized the need to capture provenance for derived datasets.

\section{USABILITY}

Usability is concerned with three major dimensions: effectiveness, efficiency, and user satisfaction. Two primary methods to achieve usability are to apply research-based human factors design principles and to employ a usercentered design approach in which users are actively involved in the design and development process. Both methods were applied on the SEEK project.

In Kepler, design principles were applied and two rounds of usability testing were conducted. Two groups of scientists (total of 33) participated in user profiling, usability testing, and a facilitated 


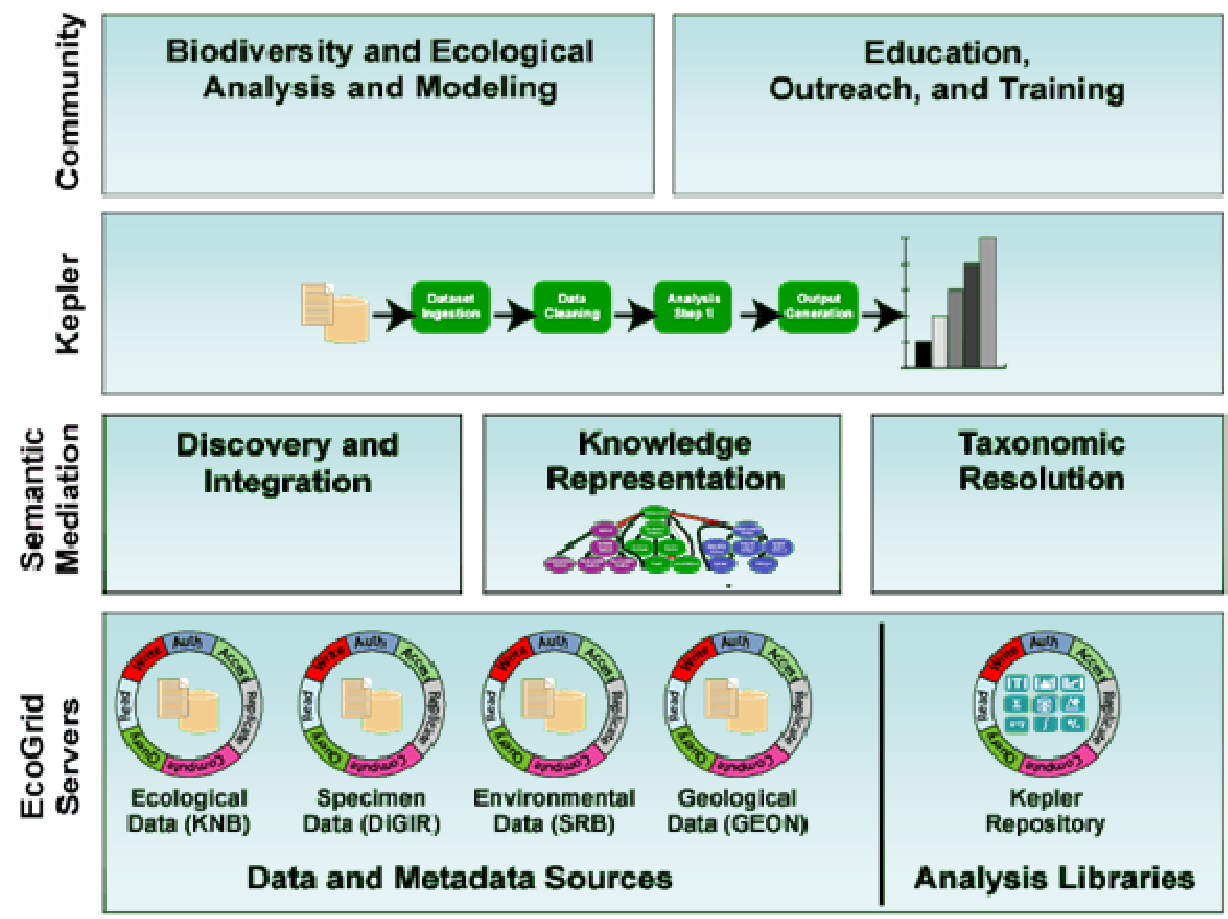

Figure 2. A schematic presentation of the architecture of the SEEK project.

group discussion on the Kepler application as part of two workshops: the first a meeting with the ecological niche modeling community discussed above, the second an ecoinformatics training workshop for early career faculty discussed below. The usability tests uncovered usability issues that were translated to 16 design recommendations $(9$ high priority). The follow-on facilitated discussions produced a list of seven new features for consideration. Table 1 provides an example of the kind of data collected from users.

Understanding the characteristics of scientists, the tools they use, and their experience level in various areas, informs design and leads to more useful technology to support their scientific efforts. To date, we have profiled 74 scientists including 39 early career faculty.

Table 2 gives a small sample of the kinds of user profile data we collected on SEEK. The sample deals with technical and technology experience -- structured query language and programming experience and data formats worked with (e.g., spreadsheets, relational databases)-- as well who uses models and amount of modeling experience. Data was self-reported via a survey on a five-point scale (1 low and 5 high). In addition to user profiling, we also mapped the tasks Kepler supports to two skills dimensions of our target users: information technology (IT) skills and quantitative skills. Figure $\mathbf{3}$ shows the basic task mapping along those dimensions.

Table 1. Features for consideration identified by user scientists during usability activities.

\begin{tabular}{|c|c|}
\hline \multicolumn{2}{|c|}{ Future Features to Consider Strongly } \\
\hline Workshop 1 & Workshop 2 \\
\hline $\begin{array}{l}\text { - Natural language summary of } \\
\text { workflows } \\
\text {-Summarization of workflow (in } \\
\text { a publishable format) } \\
\text { - Ability to assign check-points at } \\
\text { various points in the workflow so } \\
\text { that the user can check progress } \\
\text { and make decisions on whether to } \\
\text { modify or continue etc. } \\
\text { - Ability to visualize data at } \\
\text { points in the workflow } \\
\text { - Guided analysis (wizard } \\
\text { functionality for constructing } \\
\text { workflows }\end{array}$ & $\begin{array}{l}\text { - Provide browsing } \\
\text { and filtering } \\
\text { mechanisms } \\
\text { especially for data } \\
\text { and data nodes on } \\
\text { the ecogrid. } \\
\text { - Implement the } \\
\text { "most recently } \\
\text { used" concept for } \\
\text { workflows and } \\
\text { actors. }\end{array}$ \\
\hline
\end{tabular}


A listing of the major tasks is listed on the right side of Figure 3. In each quadrant, the associated tasks are displayed. Running workflows can be done by those with any combination of IT and quantitative skills. Those with higher quantitative skills can create simple or complex workflows. Technology implementation tasks (components and workflows) are done by those with high IT skills.

Kepler promotes a cycle of knowledge sharing and collaboration in science. Data, components, workflows, and knowledge about workflows created and used by one group can be utilized by other groups. Figure 4 shows some possible ways in which Kepler components can be shared between groups. Along with sharing, Kepler promotes and supports collaboration among scientists. For example a scientist with strong quantitative skills can team with a scientist with strong IT skills to produce sophisticated models and analyses.

Table 2. Profile of SEEK users (selected results).

\begin{tabular}{cccccccc}
\hline & $\#$ & $\begin{array}{c}\text { SQL } \\
\text { Exp. }\end{array}$ & $\begin{array}{c}\text { Prog } \\
\text { Exp. }\end{array}$ & $\begin{array}{c}\text { Data Format } \\
\text { Sprdsht }\end{array}$ & $\begin{array}{c}\text { Rel } \\
\text { DB }\end{array}$ & Models & Model Exp. \\
& 74 & $2.08 / 5.0$ & $2.97 / 5.0$ & $49(66 \%)$ & $20(27 \%)$ & $50(68 \%)$ & $3.03 / 5.0$ \\
Overall & 74 & $2.08 \%$ & $(77 \%)$ & $2.56 / 5.0$ \\
\hline
\end{tabular}

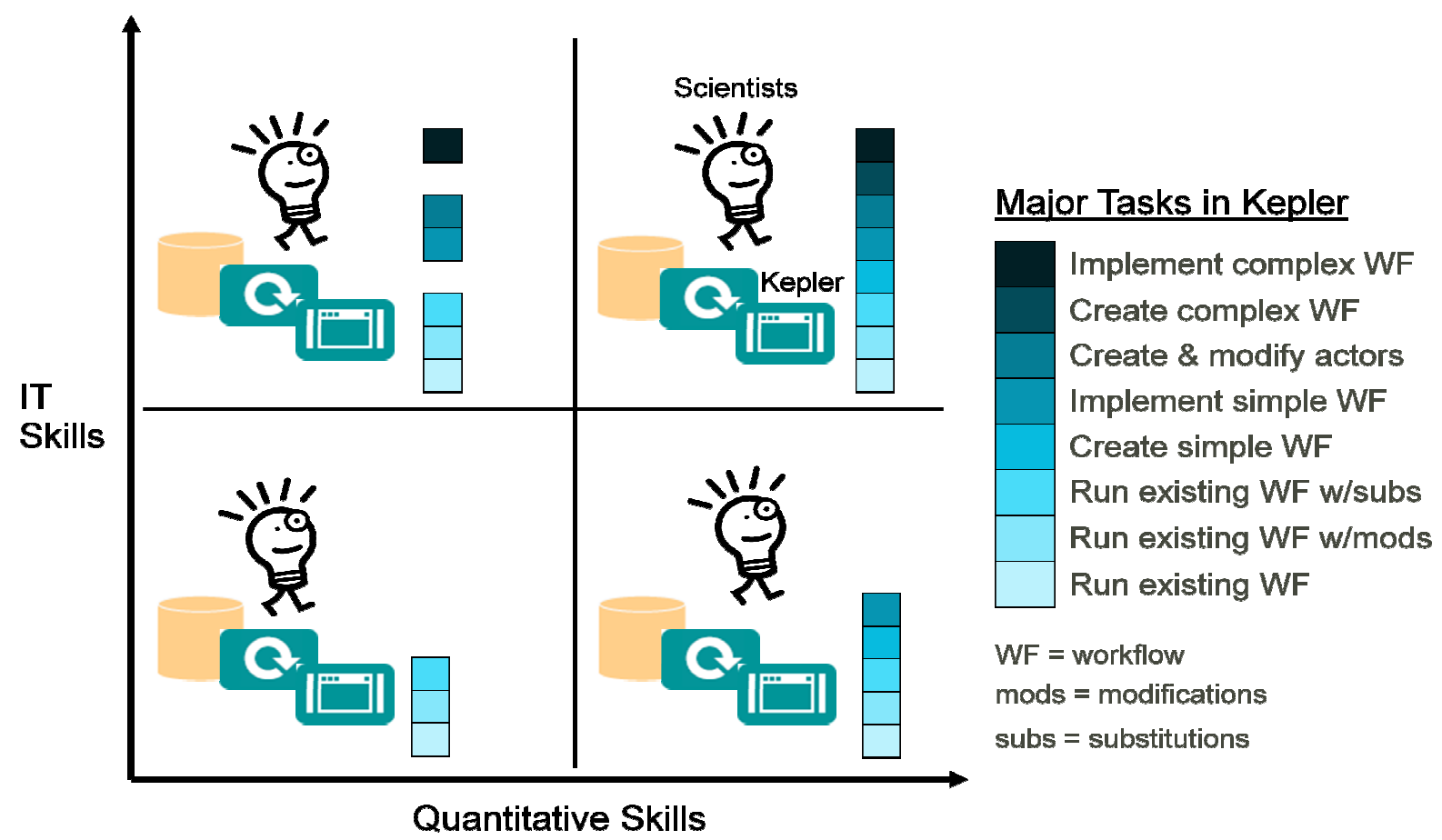

Figure 3. Task/skills mapping of Kepler users along dimensions of information technology and quantitative skills. 


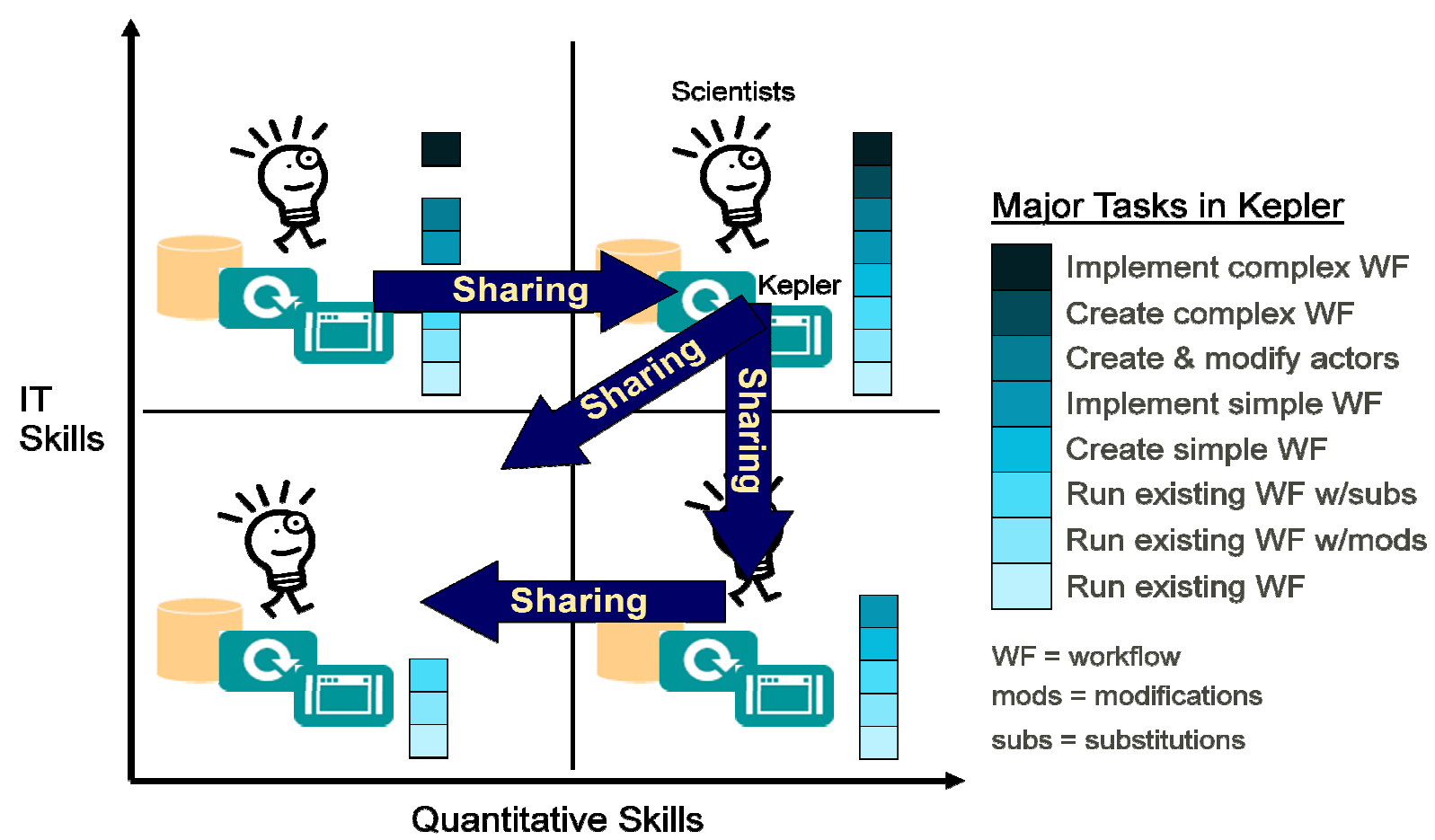

Figure 4 - Illustration of how Kepler users of varying skills combinations can share data, components, workflows, and knowledge.

As mentioned earlier, the SMS is a key feature of Kepler, aimed at making computation and data integration much easier and quicker for scientists. Ontologies, formal representations of related concepts, are being used to inform the SMS, and are exposed to users through the Kepler interface. Given the newness of ontology development, the paucity of systems that make use of ontologies, and the lack of empirical studies to inform interface design, we constructed some early user interface prototypes with input from domain scientists on the team and by applying standard design principles. These interfaces allowed users to select terms from an ontology and assign them to workflow components (the process of annotation). However, our team members were somewhat knowledgeable about ontologies, having participated in ontology design, and we were concerned that scientists with no knowledge engineering experience might have a different user interface expectation. Subsequently, we conducted a design exercise (Downey 2006) with a small number of scientists (3) as a starting point in understanding the expectations of this user group. This type of UCD activity is formative, conducted during the development process and is often exploratory (Stone et al. 2005). Results indicated a strong preference for a simple design rather than a feature-rich presentation. But the most interesting results were (1) that users expected the system to offer them contextually terms from the ontology, depending on what component was selected for annotation (i.e., to filter out any noise or irrelevant terms based on the selection), and (2) the variance among terms selected from the ontology. This UCD exercise not only revealed user interface issues and user expectations but also highlighted other areas needing research like variance among term selection and how that might affect the efficacy of the SMS.

While Kepler is a major focus, we have also applied UCD methods to other SEEK technology. Formative design and evaluation activities with small numbers of representative users provide rich design information and reveal major usability issues. To inform the design of one of our taxonomic products, we conducted three activities:

1. user analysis and profiling with four taxonomists

2. task analysis (Hackos and Redish 1998) 
3. a paper prototyping (Snyder 2003) session with an ecologist having taxonomic knowledge.

For another taxonomic product that visualizes data, we conducted an analysis with two different user groups: four taxonomists and five museum collections managers. Our purpose was to gauge whether our software included the right functionality needed by two groups.

Whenever we had the chance to apply usability engineering techniques on SEEK, we took the opportunity, whether it was a planned study with a small group or leveraging a large gathering of scientists at a workshop. Future usability activities will include remote evaluations that can take advantage of geographically dispersed users/scientists. This will provide richer and more diversified scientist input into our tools as well as the opportunity to collect more data.

\section{EDUCATION AND TRAINING}

Many of the approaches under research and development in SEEK represent completely new ways of problem solving for scientists, and depend on development of entirely new skills and new ways of thinking. Ecological studies in the late twentieth century were characterized by single investigators making original observations in field notebooks, then analyzing their data with calculators or personal computers. By the end of the century, efforts to solve global environmental issues made clear that the old ways would not suffice. Calls for cross-disciplinary, synthetic analysis over larger geographic and temporal scales enabled by advanced technologies are now pervasive throughout science, and especially within the natural sciences (Cottingham 2002, Kostoff 2002, Cash et al. 2003, Pickett et al. 2005). A new generation of scientists must emerge; scientists who are computationally savvy, can easily use technology to discover and integrate voluminous and/or heterogeneous data into their research, and who can collaborate effectively with computational scientists to construct innovative solutions to complex scientific problems.

SEEK initiated an innovative training program for early career scientists: new faculty and postdoctoral researchers who are most likely to be the early adopters of new approaches. Each year, 20 early-career scientists were chosen competitively to attend a one-week training workshop on ecoinformatics covering a broad range of cutting-edge technical concepts as well as more focused training on specific solutions being implemented by SEEK. Participants were chosen in part because they were engaged actively in research that could clearly benefit from better technical approaches. Most participants had little prior experience developing generic technical solutions to their research problems, as indicated by the user profiles mentioned above. Many were involved in modeling activities that made use of scripts within scientific modeling software such as MatLab, with little attention to useful information technology practices such as versioning, reusability, and program documentation.

The goals of the workshop were far-reaching: to provide the necessary concepts and training that would allow participants to cross the barriers and begin incorporating new technical approaches into their ongoing research. Participants were introduced to ecoinformatics and the SEEK project, and then exposed to a number of informatics topics relevant to conducting technology-empowered research (Pennington et al., 2008). Topics were covered in the order they would logically arise during a typical research project and included:

- research design for enabling technical solutions

- databases, metadata, data management and sharing

- distributed data grids

- $\quad$ analytical and visualization tools

- $\quad$ scientific workflows

- knowledge representation and ontologies.

Each workshop included pre-training and post-training surveys. An overwhelming percentage of participants agreed or strongly agreed that the workshops were useful $(84.9 \%)$. Most indicated that they learned a great deal during the workshops and that it met their expectations (90.4\%). However, follow-up contact has indicated that few have been able to incorporate these approaches into their research as effectively as they would like. Commonly stated reasons are that the week was simply not enough time, that they need additional training, and that they need mentoring as they actually start trying to use these new techniques. Additional resources will be needed to develop more strategies for 
bridging the gap, which is clearly broader than one technology research project can span.

\section{RESEARCH IMPLICATIONS}

One of the interesting benefits of applying UCD techniques on SEEK was that other areas of UCD research emerged as a result, within and between disciplines. Within usability, a new testing method is being developed: group usability testing. This came about as a result of a pragmatic decision to take advantage of groups of scientists gathered for workshops, and because of limited time. Instead of conducting traditional individual testing, we conducted group usability testing (Downey 2007). Future plans include conducting the same test both individually and as a group and comparing results. This research has the potential to improve the efficiency of usability testing.

Several research implications arose during the design activity on annotating workflow components from formal ontologies, described in detail in (Downey 2006). They can be categorized into two broad areas: user interface design issues and annotation issues. In the short term, we plan to research the variance of term selection by users in the annotation process.

From a broader perspective, our experience on the SEEK project has highlighted the need for theories and models of collaboration between scientists and technologists. We have initiated new research efforts towards this end ${ }^{6}$, searching for better ways to enable the incorporation of new technologies into scientists' work processes (Pennington, 2008). Conversely, we also need better ways to determine user needs for innovative technologies, when those technologies are designed to fundamentally change the work tasks that normally inform design. Lastly, we have begun to investigate mechanisms for designing technologies that simultaneously meet the needs of multiple collaborating user groups (Pennington et al. 2007).

\section{SUMMARY}

UCD enhances and exploits the broadening scope of informatics that includes humans, technology and knowledge. The benefits of UCD on the SEEK project are clear. We believe that the usercentered design approach is essential for

\footnotetext{
${ }^{6}$ http://www.scidesign.org.
}

successfully bridging the gap between technology and science. Individuals with this perspective and training have also been identified by the National Science Foundation (Atkins et al. $)^{7}$

\begin{abstract}
"The need for a new workforce - a new flavor of mixed science and technology professional - is emerging. These individuals have expertise in a particular domain science area, as well as considerable expertise in computer science and mathematics. Also needed in this interdisciplinary mix are professionals who are trained to understand and address the human factors dimensions of working across disciplines, cultures, and institutions using technology-mediated collaborative tools. Prior work on computer-supported collaborative work and social dimensions of collaboratories needs to be better codified, disseminated, and applied in the design and refinement of new knowledge environments for science based on cyberinfrastructure."
\end{abstract}

In order to build the best scientific tools possible, to promote and enhance collaboration and to enable new analyses and discoveries -involving scientists in the design and development of scientific tools is essential. The user-centered design approach is a proven methodology for achieving user involvement and is the bridge between technology and science.

\section{ACKNOWLEDGEMENTS}

We acknowledge all the scientists who have participated in the user-centered design activities in SEEK, and all the members of the SEEK team for their support, enthusiasm, and contributions. Finally, we thank the SEEK executive staff for their support and encouragement in our work.

\section{REFERENCES}

Altintas I., Berkley C., Jaeger E., Jones M., Ludäscher B., Mock S. 2004. Kepler: An Extensible System for Design and Execution of Scientific Workflows. Proceedings of 16th International Conference on Scientific and Statistical Database Management (SSDBM). Santorini Island, Greece. June 2004.

\footnotetext{
${ }^{7}$ http://www.nsf.gov/cise/sci/reports/atkins.pdf.
} 
Araújo, M. B., Pearson R. G., Thuiller W., Erhard M. 2005. Validation of species-climate impact models under climate change. Global Change Biology 11:1504-1513.

Atkins, D. (Chair). 2003. Revolutionizing science and engineering through cyberinfrastructure: report of the National Science Foundation Blue-Ribbon Advisory Panel on Cyberinfrastructure. ${ }^{8}$

Barbaut R., Sastrapadja S. 1995. Generation maintenance and loss of biodiversity. Heywood, V. H., editor. Global Biodiversity Assessment. Cambridge University Press. Cambridge. pp. 193-274.

Beerling D. J., Huntley B,, Bailey J. P. 1995. Climate and the distribution of Fallopia japonica: use of an introduced species to test the predictive capacity of response surfaces. Journal of Vegetation Science 6:269-282.

Bias R., Mayhew D. 2005. Cost-Justifying Usability, Second Edition. Morgan Kaufmann, San Francisco, CA..

Bowers S., Lin K., Ludäscher B. 2004. On integrating scientific resources through semantic registration. Proceedings of the 16th International Conference on Scientific and Statistical Database Management (SSDBM). Santorini Island, Greece. June 2004.

Bowers S., Ludäscher B. 2004. An ontology-driven framework for data transformation in scientific workflows. Proceedings of the International Workshop on Data Integration in the Life Sciences (DILS). Springer, LNCS, volume 2994.

Bowers S., Ludäscher B. 2003. Towards a generic framework for semantic registration of scientific data. Proceedings of the Workshop on Semantic Web Technologies for Searching and Retrieving Scientific Data, CEUR Workshop Proceedings, volume 83, ISSN 16130073.

Carpenter G., Gillison A. N., Winter J. 1993. DOMAIN: A flexible modeling procedure for mapping potential distributions of animals and plants. Biodiversity and Conservation 2:667-680.

Cash D. W., Clark W. C., Alcock F., Dickson N. M., Eckley N., Guston D. H., Jager J., Mitchell R. B. 2003. Knowledge systems for sustainable development. PNAS 100:8086-8091.

Cottingham, K. L. 2002. Tackling biocomplexity: The role of people, tools, and scale. BioScience 52:793-799.

Downey L. L. 2006, Designing Annotation Mechanisms with Users in Mind: A Paper Prototyping Case Study from the Scientific Environment for Ecological Knowledge (SEEK) Project, Semantic Web User Interaction Workshop, Fifth International Semantic Web Conference. Athens, GA.

Downey L. L. 2007. Group usability testing: evolution in usability techniques. Journal of Usability Studies [Internet]. [cited 2007]. 2:133-144.

Hackos J. T., Redish J. C. 1998. User and Task Analysis for Interface Design. John Wiley \& Sons, Inc., New York, NY. pp 71-72.

Kostoff R. N. 2003. Overcoming specialization. BioScience 52:937-941.

Ludäscher B., Altintas I., Berkley C., Higgins D., JaegerFrank E., Jones M., Lee E., Tao J., Zhao Y. 2006. Scientific workflow management and the Kepler system.
Concurrency and Computation: Practice \& Experience 18:1039-1065.

Madin J., Bowers S., Krivov S., Pennington D., Schildhauer M., Villa F. (submitted) An ontology for describing and synthesizing ecological observation data. International Journal of Ecological Informatics, Special Issue on Data Management.

Martínez-Meyer E., Peterson A. T., Hargrove W. W. 2004. Ecological niches as stable distributional constraints on mammal species, with implications for Pleistocene extinctions and climate change projections for biodiversity. Global Ecology and Biogeography 13:305314.

Michener W. K., Beach J. H., Jones M. B., Ludaescher B., Pennington D. D., Pereira R. S., Rajasekar A., Schildhauer M., 2007. A knowledge environment for the biodiversity and ecological sciences, Journal of Intelligent Information Systems. 29:111-126

Nix H. A. 1986. A biogeographic analysis of Australian elapid snakes. Longmore R, editor. Atlas of elapid snakes of Australia. Australian Flora and Fauna Series 8:4-15.

Pennington, D. 2008. Cross-disciplinary collaboration and learning. Ecology and Society. 13:8.

Pennington, D. 2008. A view from the trenches. Computing in Science and Engineering, 10:28-33.

Pennington D., Higgins D., Peterson A. T., Jones M. B., Ludaescher B., Bowers S. 2007. Ecological niche modeling using the Kepler workflow system. Taylor I, Gannon D, Deelman E, Shields M, editors, Workflows for e-Science. Springer-Verlag.

Pennington D. D., Madin J., Villa F., Athanasiadis I. N. 2007. Computer-supported collaborative knowledge modeling in ecology. Proceedings of the Workshop on Social and Collaborative Construction of Structured Knowledge, $16^{\text {th }}$ International World Wide Web Conference (WWW2007). Banff, Canada, May 8, 2007.

Peterson A. T., Vieglais D. A. 2001. Predicting species invasions using ecological niche modeling. BioScience 51:363-371.

Pickett S. T. A., Cadenasso M. L., Grove J. M. 2005. Biocomplexity in coupled natural-human systems: A multidimensional framework. Ecosystems 8:225-232.

Pimm S. L., Raven P. 2000. Extinction of numbers. Nature 403:843-845.

Snyder C. 2003. Paper Prototyping: The Fast and Easy Way to Design and Refine User Interfaces, Elsevier, San Francisco, CA.

Stone D., Jarrett C., Woodroffe M., Shailey M. 2005. User Interface Design and Evaluation, Morgan Kaufmann, San Francisco, CA. pp 552.

Waide R. B., Willig M. R., Steiner C. F., Mittelbach G., Gough L., Dodson S. I., Juday G. P., Parmenter R. 1999. The relationship between productivity and species richness. Annual Review of Ecology and Systematics 30:257-300.

Walker P. A., Cocks K. D. 1991. HABITAT: A procedure for modelling a disjoint environmental envelope for a plant or animal species. Global Ecology and Biogeography Letters $1: 108-118$

8 http://www.nsf.gov/od/oci/reports/atkins.pdf. 